\title{
In this issue
}

Financial Statistics is divided into two parts: the first part (chapters 1 to 7 ) contains tables that are updated as and when new information becomes available, and the second part (chapters 8, 9, 11, 12 , and 14) contains tables that form a consistent dataset which is updated once per quarter. The consistent dataset has been updated this month and includes figures up to 2010 Q2 consistent with the Quarterly National Accounts Statistical Bulletin published on Tuesday 28 September 2010.

The European System of Accounts 1995 (ESA95) have been presented in Financial Statistics since October 1998.

Supplementary tables: tables S29 'Government deficit and debt under the Maastricht Treaty: summary table' and S29B 'General government gross debt at nominal value consolidated' are included in this edition.

The tables in part one contain the latest figures available for publication, which may not have been incorporated into the consistent data set published in part two. Thus, where the same series appears in part one and part two, the figures may be different. Further details are given on pages 11 and 159.

\section{General notes}

Data sources. The name of the department or organisation providing the statistics is shown under each table. Some of the statistics provided by departments are actually collected by other organisations and the assistance provided by these organisations, too numerous to mention individually, is gratefully acknowledged.

Provisional data. Some figures are provisional and may be revised in later issues. This applies particularly to data for the most recent time periods.

Area covered. Except where otherwise stated, the statistics relate to the United Kingdom of Great Britain and Northern Ireland.

Change of basis. A line across a column between two consecutive figures indicates that the figures above and below the line have been compiled on different bases and are not strictly comparable. These breaks are described in the Financial Statistics Explanatory Handbook.

Rounding the figures. Where figures have been rounded there may be a slight discrepancy between the total and the sum of the constituent items.

Symbols and conventions. The following symbols are used throughout:

.. not available.

- $\quad$ nil or less than half the final digit.

$\dagger \quad$ indicates a new entry or the earliest to have been revised since the previous issue.

Financial years. These are indicated by the format 2010/09. 
Series identifiers. A unique four letter identifier (for example, RURQ) is associated with each series and printed above it or to its left in the tables. The identifier provides a cross-reference between the tables and the National Statistics Databank (see overleaf). If you need further information about the data, please quote the relevant identifier when you contact us.

\section{Explanatory Handbook}

The 2010 edition of Financial Statistics Explanatory Handbook (price £52.50) was published in December 2009. This companion volume contains notes and definitions which are essential to understanding the tables and explaining the relationships between them.

\section{ONS Online Services}

\section{www.ons.gov.uk}

Web-based access to time series, cross-sectional data and metadata, available using the site search and index functions from the homepage. Download many datasets, in whole or in part, or consult directory information for all ONS statistical resources, including censuses, surveys, periodicals and enquiry services. Information is posted as PDF electronic documents or in XLS and CSV formats, compatible with most spreadsheet packages.

\section{Time Series Data}

Access to around 40,000 time series, of primarily macro-economic data, drawn from the main tables in a range of our major economic and labour market publications. Download complete releases, or view and download your own customised selection of individual time series.

For more details about these services:

E-mail:

statbase@statistics.gov.uk

Telephone:

01329444366

ONS website:

www.ons.gov.uk

Mailing Address:

Office for National Statistics

Government Buildings

Cardiff Road

Newport

NP10 8XG 